\title{
Effect of small extracellular vesicles derived from IL-10-overexpressing mesenchymal stem cells on experimental autoimmune uveitis
}

\author{
Yongtao $\mathrm{Li}^{1 \dagger}$, Xinjun Ren ${ }^{1 \dagger}$, Zhihui Zhang ${ }^{1}$, Yanan Duan ${ }^{1}$, Huan $\mathrm{Li}^{1}$, Shuang Chen ${ }^{1}$, Hui Shao ${ }^{2}$, Xiaorong Li ${ }^{1}$ and
} Xiaomin Zhang ${ }^{1 *}$ (D)

\begin{abstract}
Background: Autoimmune uveitis is a sight-threatening intraocular inflammation mainly caused by immune dysregulation. The development of safe and effective therapeutic approaches is urgently needed. Small extracellular vesicles (sEVs) derived from mesenchymal stem cells (MSCs) have been demonstrated to inhibit autoimmune responses; however, the immunosuppressive effect of MSC-sEVs is too weak for clinical transfer. In the current study, we investigated the therapeutic effect of IL-10-overexpressing MSC-sEVs (sEV-IL10) on experimental autoimmune uveitis (EAU) and studied the underlying mechanism.
\end{abstract}

Methods: Mice were randomly grouped and received a single tail vein injection of different sEVs $(50 \mu \mathrm{g})$ or PBS on day 11 post-immunization. The clinical and histological scores were graded, and the percentage of Thelper cell was measured. To investigate the effect of sEVs on the proliferation of T-cells and the differentiation of Th1, Th17 and Treg cells, T-cells were cocultured with sEVs under the corresponding culture conditions. After labeled with PKH-26, sEVs were traced both in vivo and in vitro.

Results: Compared with normal or vector sEV-treated groups, mice in the sEV-IL10-treated group had lower clinical and histological scores with lower percentages of Th1 and Th17 cells in the eyes and higher percentages of Treg cells in the spleen and draining lymph nodes (LN). Furthermore, sEV-IL10 enhanced the suppressive effect of MSC-sEVs on the proliferation of T-cells and differentiation of Th1 and Th17 cells, whereas upregulated the differentiation of Treg cells. Both in vivo and in vitro experiments demonstrated that MSC-sEVs were rapidly enriched in target tissues and internalized by T-cells.

Conclusion: These results suggested that sEV-IL10 effectively ameliorates EAU by regulating the proliferation and differentiation of T-cells, indicating sEVs as a potential novel therapy for autoimmune uveitis or other autoimmune diseases.

Keywords: Autoimmune uveitis, Interleukin 10, Mesenchymal stem cell, Small extracellular vesicle, T-cell

\footnotetext{
*Correspondence: xzhang08@tmu.edu.cn

${ }^{\dagger}$ Yongtao Li and Xinjun Ren have contributed equally to this study

${ }^{1}$ Tianjin Key Laboratory of Retinal Functions and Diseases, Tianjin Branch of National Clinical Research Center for Ocular Disease, Eye Institute and School of Optometry, Tianjin Medical University Eye Hospital, Tianjin, China

Full list of author information is available at the end of the article
}

\section{Background}

Autoimmune uveitis is one of the leading causes of blindness owing to its frequent recurrence. Corticosteroids and immunosuppressive agents are the most commonly prescribed drugs for the treatment of uveitis [1]. However, their clinical applications have been limited by longterm systemic side effects and the unresponsiveness of original author(s) and the source, provide a link to the Creative Commons licence, and indicate if changes were made. The images or other third party material in this article are included in the article's Creative Commons licence, unless indicated otherwise in a credit line to the material. If material is not included in the article's Creative Commons licence and your intended use is not permitted by statutory regulation or exceeds the permitted use, you will need to obtain permission directly from the copyright holder. To view a copy of this licence, visit http://creativecommons.org/licenses/by/4.0/. The Creative Commons Public Domain Dedication waiver (http://creativeco mmons.org/publicdomain/zero/1.0/) applies to the data made available in this article, unless otherwise stated in a credit line to the data. 
some patients. Biological agents, especially anti-tumor necrosis factor- $\alpha$ (TNF- $\alpha$ ) monoclonal antibodies, have been reported to be effective in some refractory cases; however, they are limited to patients at high risk of infection [2,3]. Therefore, there is an urgent need to develop more effective and safer improved therapeutic approaches.

Mesenchymal stem cells (MSCs) are adult stem cells with the capacity for multilineage differentiation and self-renewal. In particular, MSCs have strong immunosuppressive functions and can suppress various immune responses, including autoimmunity and allograft rejection, without weakening anti-infection immunity $[4,5]$. Previous studies have demonstrated that MSCs can significantly alleviate experimental autoimmune uveitis (EAU) in animal models [4, 6-11]. However, cell-based therapy not only raises the challenge of quality control regarding the preservation and transport of cell products, but also increases the risk of vessel obstruction, malignant transformation, and allogenic immunological rejection [12-15].

Exosomes are tiny vesicles (ranging from 40 to $150 \mathrm{~nm}$ in diameter) with a lipid bilayer membrane structure containing functional molecules, such as proteins, mRNAs, microRNAs, and DNAs. Considering that current separation protocols cannot completely remove nonexosome vesicles and lack evidence of the endosomal biogenesis pathway, the term small extracellular vesicles (sEVs) has been recommended [16]. Accumulating evidence have suggested that $\mathrm{sEVs}$ mediate the paracrine pathway of MSCs, exerting biological functions similar to parent cells [17-19]. Compared with cells, sEVs do not have the ability to replicate, differentiate, or mutate, and are easy to store and transport [20]. In addition, as sEVs been show to mediate intercellular communication though transferring their cargo to recipient cells, and their lipid bilayer membrane can protect the enwrapped proteins and miRNAs from degradation, sEVs have been widely used as drug carriers [21, 22]. Therefore, as a novel type of cell-free therapy, sEV-based therapy is expected to be a desirable surrogate for stem cell therapy [23]. Our previous studies revealed that MSC-derived sEVs (MSC-sEVs) could inhibit EAU; however, this involved the administration of large doses and frequent periocular injections [24].

Interleukin 10 (IL-10) is a major immunoregulatory cytokine that contributes to immune homeostasis and is a key factor mediating the immunosuppression of MSCs [25]. However, the application of IL-10 for the treatment of autoimmune diseases has not been successfully translated into clinical practice because of its short half-life in vivo [26]. Therefore, in this study, we utilized MSCsEVs as carriers for IL-10 to protect it from degradation and enhance its half-life in vivo [26]. We demonstrated that IL-10-overexpressing MSC-sEVs (sEV-IL10) dramatically enhanced the therapeutic effect of MSC-sEVs on EAU by suppressing the proliferation of uveitogenic T-cells and differentiation of Th1/Th17 cells and promoting the differentiation of Treg cells. We also found that sEV-IL10 were internalized by T-cells in vitro and rapidly enriched in target tissues in EAU mice after intravenous injection (i.v.).

\section{Methods \\ Animals}

All animal procedures conformed to the statement for the use of animals in ophthalmic and vision research of the Association for Research in Vision and Ophthalmology (ARVO) and approved by the Laboratory Animal Care and Use Committee of Tianjin Medical University Eye Hospital (TMUEC) (No. TJYY2019103022). Female C57BL/6 J mice (B6) (7-week-old) were purchased from Vital River Experimental Animal Center (Beijing, China) and housed under specific pathogen-free (SPF) conditions in the animal center of TMUEC at $21-25{ }^{\circ} \mathrm{C}$ and $45-65 \%$ humidity with a $12 \mathrm{~h}$ day/dark cycle.

\section{Isolation and culture of mesenchymal stem cells}

Human umbilical cord MSCs were provided by Beilai Biological Co., Ltd. (Beijing, China). The isolation and culture of MSCs were performed as previously reported [24]. MSCs were identified by their capacity to differentiate into adipocytes, chondrocytes, and osteocytes when cultured under appropriate conditions in vitro [24]. Further characterization was based on the expression of the CD90, and CD29 markers, and the absence of the CD34 and CD45 markers, as previously described [24].

\section{Production and transduction of lentiviruses}

Briefly, IL-10-overexpressing or empty vector plasmids (pCDH-CMV-MCS-EF1-copGFP) (Hanbio Biotechnology, Shanghai, China) were transfected into human embryonic kidney $293 \mathrm{~T}$ cells (HEK-293 T) along with PMD2G and PSPAX2 (Hanbio Biotechnology) using lipofectamine 2000 (Invitrogen, California, USA) according to the manufacturer's instructions. Lentiviruses in the culture supernatant were collected at 48 and $72 \mathrm{~h}$ after transfection and filtered $(0.22 \mu \mathrm{m})$. The supernatant was concentrated by ultracentrifugation at $72000 \times g$ for $2 \mathrm{~h}$, and the viral titer was then determined using the serial dilution method [27].

\section{Transfection and supernatant collection}

MSCs at passage 2 grown to $60 \%$ confluency were infected with lentivirus with a multiplicity of infection (MOI) of 50 and incubated with $8 \mu \mathrm{g} / \mathrm{mL}$ polybrene 
(Sigma-Aldrich, St. Louis, USA) for $8 \mathrm{~h}$. MSCs from passages 3-5 were used for the production of sEVs. MSCs were cultured in complete DMEM/F-12 media (Gibco, California, USA) containing 10\% FBS (Gibco) and 100 $\mathrm{U} / \mathrm{mL}$ penicillin and streptomycin (Gibco). When cells fusion reached $60 \%$, media were replaced with serumfree MSC XF Basal medium (BI, Kibbutz, Israel) supplemented with $0.6 \%$ MSC XF Supplement Mix (BI). After $48 \mathrm{~h}$ of incubation, the culture supernatants were harvested.

\section{Quantitative Real-time RT-PCR (qRT-PCR)}

Total RNA was extracted using the TRIzol reagent (Invitrogen) according to the manufacturer's instructions and transcribed into cDNA using a RevertAid First Strand cDNA Synthesis Kit (Thermo Fisher, Massachusetts, USA). Each qPCR reaction in 384-well plates contained FastStart SYBR Green Master (Roche, Basel, Switzerland), cDNA, and $0.25 \mu \mathrm{M}$ forward and reverse primers. The relative levels of mRNA expression of target genes were calculated using the $2^{-\Delta \Delta C q}$ method, with GAPDH as an internal standard [28]. The sequences of each primer were as follows: IL-10 forward, 5'-TGAAAACAAGAGCAAGGCCG-3', reverse: 5'-ATAGAGTCGCCACCCTGATG-3'; GAPDH forward: 5'-AATGGGCAGCCGTTAGGAAA-3', reverse: $5^{\prime}$ GCG CCCAATACGACCAAATC-3'.

\section{Isolation of small extracellular vesicles}

The generated sEVs were purified using the ultracentrifugation method. CM was centrifuged at $200 \times g$ for $10 \mathrm{~min}$ at $4{ }^{\circ} \mathrm{C}$, followed by centrifugation at $2000 \times g$ for $20 \mathrm{~min}$ at $4{ }^{\circ} \mathrm{C}$ to remove cell debris, and an additional round of centrifugation at $10000 \times g$ for $30 \mathrm{~min}$ at $4{ }^{\circ} \mathrm{C}$ to remove apoptotic bodies. sEVs were harvested by ultracentrifugation twice at $110000 \times g$ for $70 \mathrm{~min}$ at $4{ }^{\circ} \mathrm{C}$. Pellets were further purified by resuspension in PBS (Gibco) and ultracentrifugation at $110000 \times g$ for another $70 \mathrm{~min}$ at $4{ }^{\circ} \mathrm{C}$ to remove any contaminating proteins. All ultracentrifugation steps were performed on an Optima XLA/I centrifuge with an An-45Ti rotor (Beckman-Coulter, California, USA).

\section{Characterization of small extracellular vesicles}

sEVs were characterized according to previously published protocols [24]. In brief, after fixation with $4 \%$ paraformaldehyde (Sigma-Aldrich), sEV sample was dropped on a carbon copper grid, stained with a $2 \%$ uranyl acetate solution (Sigma-Aldrich), and photographed using a Phillips CM10 electron microscope (Phillips Electron Optics, Eindhoven, The Netherlands). The size distribution of sEV samples was determined using a nanoparticle analysis system (NanoSight Ltd, Amesbury, UK). The expression of TSG101 and CD9 sEV surface markers was identified by western blotting. sEV samples $(10 \mu \mathrm{g})$ were separated by polyacrylamide gel electrophoresis (SDS-PAGE) after heat denaturation at $95{ }^{\circ} \mathrm{C}$ for 5 min. Proteins were transferred onto PVDF membranes (Sigma-Aldrich) using a wet transfer electrophoresis tank at $90 \mathrm{~V}$ for $2 \mathrm{~h}$ and incubated in 5\% skim milk in PBS supplemented with $0.05 \%$ Tween- 20 for $1 \mathrm{~h}$ at $25^{\circ} \mathrm{C}$. Quantification of sEVs was performed using the BCA method.

\section{Induction and treatment of experimental autoimmune uveitis}

For EAU induction, mice were subcutaneously immunized with an emulsion containing equal volumes of incomplete Freund's adjuvant (IFA) (Sigma-Aldrich) with $5 \mathrm{mg} / \mathrm{mL}$ desiccated Mycobacterium tuberculosis (Sigma-Aldrich) and $250 \mu \mathrm{g} \mathrm{IRBP}_{651-670}$ (Hanhong group, Shanghai, China) in PBS, distributed at 4 spots on the tail base and flank. Mice were intraperitoneally administered 500 ng pertussis toxin (PTX) (List Biological Laboratories, California, USA) on the day of immunization and $24 \mathrm{~h}$ post-immunization.

First, mice were randomly grouped ( $n=6$ mice) and received i.v. injection of recombinant IL-10 or equal volume of PBS, respectively. Mice in single injection group received a single i.v. injection of $500 \mathrm{ng}$ recombinant IL-10 in $200 \mu \mathrm{l}$ PBS on day 11 post-immunization. Mice in multiple injection group received i.v. injection of $500 \mathrm{ng}$ recombinant IL-10 in $200 \mu \mathrm{l}$ PBS for 5 consecutive days (once a day from day 11 to day 15 post-immunization).

Next, mice were randomly grouped ( $n=6$ mice) and received a single tail vein injection of sEVs or PBS on day 11 post-immunization. For contrast experiments, mice were injected with $50 \mu \mathrm{g} s E V-\mathrm{N}$, IL10-overexpressing MSC-sEVs (sEV-IL10), vector-infected MSC-sEVs (sEV$\mathrm{V})$, or equal volume of PBS, respectively.

\section{Clinical and histological assessment of experimental autoimmune uveitis}

Clinical and histological grading was scored as described by Caspi et al. [29]. The retinal status was examined once every other day using an indirect binocular ophthalmoscope through a $90 \mathrm{D}$ fundus lens starting on day 8 post-immunization. Mice were killed on day 18 postimmunization, and their eyeballs were collected and fixed in $4 \%$ paraformaldehyde. Fixed retinal tissues were embedded in paraffin and cut into 5 - $\mu$ m-thick sections. The sections were then stained with hematoxylin and eosin (H\&E) according to standard procedures.

\section{Labeling and tracing of small extracellular vesicles}

Purified sEVs were labeled using a PKH26 kit (SigmaAldrich) according to the manufacturer's protocol. 
Labeled sEVs were washed twice in PBS by centrifuged at $110000 \times g$ for $70 \mathrm{~min}$.

To trace sEVs in vivo, $100 \mu \mathrm{g}$ PKH-26 labeled sEVs was injected into EAU (11 d post-immunization) or naïve mice via the tail vein. Mice were killed at 24, 48, or $72 \mathrm{~h}$ post-injection. Tissue samples (eyeball, spleen, lymph node, heart, liver, and kidney) were collected immediately after killing and embedded in optimal cutting temperature (OCT) (Thermo Fisher) compound to obtain frozen sections $(8 \mu \mathrm{m})$. Frozen sections were then fixed with paraformaldehyde, incubated with $5 \mathrm{mg} / \mathrm{mL}$ DAPI for nuclei staining, and visualized under a LSM510 confocal microscope (Zeiss, Oberkochen, Germany).

To trace sEVs in vitro, purified CD4+T-cells were isolated from spleens of $\mathrm{B} 6$ mice using a negative CD4+T-cell isolation kit (Invitrogen) and cultured in complete RPMI (Gibco) in a 96-well plate precoated with $10 \mu \mathrm{g} / \mathrm{mL}$ anti-CD3 plus $1 \mu \mathrm{g} / \mathrm{mL}$ anti-CD28 (BioLegend, London, UK). After $24 \mathrm{~h}$ of incubation, $20 \mu \mathrm{g} / \mathrm{mL}$ PKH-26 labeled sEVs were added. CD4+T-cells were collected after 1,3 , and $6 \mathrm{~h}$ of coculture with sEVs and then spread on an adhesive glass slide. Cells were fixed with $4 \%$ paraformaldehyde for $30 \mathrm{~min}$ and blocked with PBS containing 5\% normal goat serum and $0.3 \%$ Triton (Sigma) for $1 \mathrm{~h}$. FITC-conjugated anti-CD4 Ab and DAPI (Sigma) were used to stain cellular membranes and nuclei, respectively. Immunofluorescence intensity was visualized using confocal microscopy (LSM510; Zeiss).

\section{Isolation and analysis of infiltrating cells}

Eyeballs were enucleated under anesthesia on day 18 post-immunization. The optic nerve, cornea, and lens were removed. The remaining tissues were squashed through a $70-\mu \mathrm{m}$ cell strainer. After centrifugation, enzyme digestion was performed using $1 \mathrm{mg} / \mathrm{mL}$ collagenase D (Sigma-Aldrich) for $45 \mathrm{~min}$. Cells were centrifuged, washed with PBS, and resuspended in CM. Spleen and draining lymph nodes (cervical and mandibular lymph node) were also isolated under anesthesia on day 18 post-immunization. After squashed through a 70- $\mu \mathrm{m}$ cell strainer and lysed with red blood cell lysis buffer (Sigma), spleen and draining lymph nodes were prepared into single cell suspensions.

Part of cells were then stimulated with $50 \mathrm{ng} / \mathrm{mL}$ PMA (Sigma), $1 \mu \mathrm{g} / \mathrm{mL}$ ionomycin (Sigma), and $1 \mu \mathrm{g} / \mathrm{mL}$ brefeldin A (Abcam, Cambridge, USA) for 5 h. Finally, stimulated cells were stained for further intracellular cytokine analysis.

\section{T-cell proliferation assay}

Purified CD4+T-cells isolated from lymph nodes and spleens of naive mice using a negative CD4+ T-cell isolation kit (Miltenyi Biotec, California, USA). The purified
CD4+ T-cells were then labeled with $1 \mu \mathrm{M}$ CFSE (Invitrogen) for $10 \mathrm{~min}$, and seeded in 96-well plates precoated with $10 \mu \mathrm{g} / \mathrm{mL}$ anti-mouse CD3 $\mathrm{mAb}$ and $2 \mu \mathrm{g} / \mathrm{mL}$ antimouse CD28 mAb (BioLegend) at a density of $5 \times 10^{5}$ cells per well. Cell growths were analyzed by FACS at $72 \mathrm{~h}$ post-culture.

\section{Ex vivo T-cell recall assay}

T-cells $\left(4 \times 10^{5}\right.$ cells/well $)$ were isolated from the draining lymph nodes (cervical and mandibular lymph node) and spleens of EAU mice on day 14 post-immunization through a nylon wool column and cocultured with syngeneic irradiated (30 Gy) APCs $\left(4 \times 10^{5}\right.$ cells/well) in 96-well plates with graded doses of $\operatorname{IRBP}_{651-670}(0,1$, 10 , and $20 \mu \mathrm{g} / \mathrm{mL}$ ), in a total $200 \mu \mathrm{L}$ volume. After $72 \mathrm{~h}$ of culture, the BrdU assay was performed to assess the proliferation of T-cells using the BrdU Cell Proliferation Assay Kit (Abcam). The IFN- $\gamma$ and IL-17A concentrations in the cell culture supernatants (with $20 \mu \mathrm{g} / \mathrm{mL}$ $\mathrm{IRBP}_{651-670}$ ) were measured using ELISA kits according to the manufacturer's instructions (R\&D Systems).

\section{In vitro T-cell differentiation assay}

Naïve CD4+CD45RA+T-cells were enriched using an immunomagnetic $\mathrm{CD} 4+\mathrm{T}$ cell isolation kit (Miltenyi Biotec). Cells were seeded in anti-CD3/CD28 precoated 96-well plates at a density of $2 \times 10^{5}$ cells/well and cultured under Th1, Th17, and Treg polarizing conditions. For Th1 polarization, cells were cultured in $\mathrm{X}$-Vivo15 serum-free medium (Lonza, Basel, Switzerland) supplemented with IL-12 $(10 \mathrm{ng} / \mathrm{mL})$ and anti-IL4 $(10 \mu \mathrm{g} / \mathrm{mL})$. For Th17 polarization, cells were cultured in $\mathrm{X}$-Vivo15 serum-free medium supplemented with IL-6 $(30 \mathrm{ng} / \mathrm{mL})$, anti-IL4 $(10 \mu \mathrm{g} / \mathrm{mL})$, anti-IFN- $\gamma(10 \mu \mathrm{g} /$ $\mathrm{mL})$, IL-23 (6 ng/mL), and TGF- $\beta 1(2.5 \mathrm{ng} / \mathrm{mL})$. For Treg polarization, cells were cultured in X-Vivo15 serum-free medium supplemented with TGF- $\beta 1(5 \mathrm{ng} / \mathrm{mL})$ and IL-2 $(20 \mathrm{ng} / \mathrm{mL})$. After $5 \mathrm{~d}$ of culture, cells were collected and analyzed by FACS. Recombinant cytokines were purchased from R\&D Systems (Minneapolis, USA), while antibodies against these cytokines were purchased from BD Biosciences (California, USA).

\section{Flow cytometry analysis}

Cells were stained with fluorescein-conjugated antimouse CD4 and washed twice with wash buffer (PBS plus $2 \%$ BSA). For intracellular staining, fixation and permeabilization of cells were further preformed. Then, the samples were intracellular stained for fluorescein-conjugated antibodies specific for IFN- $\gamma$, IL-17A, and Foxp3 in permeabilization wash buffer. Unless otherwise noted, antibodies used for staining were purchased from BioLegend. 
Flow cytometric analysis was performed with a BD FACSCalibur flow cytometry, and acquired data were analyzed by FlowJo software (Oregon, USA).

\section{Statistical analysis}

All experiments were independently repeated 3 times. All data were analyzed using the version 22.0 SPSS software (IBM, Chicago, USA) and presented as the mean \pm SD. Unpaired Student's $t$-test was used to assess the significance between 2 groups. Experimental data for multiple group comparisons were analyzed using one-way ANOVA. Differences were considered statistically significant at $P<0.05$.

\section{Results}

\section{Characterization of mesenchymal stem cell-small extracellular vesicles}

Prior to using isolated MSCs, we characterized cells for the positive expression of the CD90, and CD29 markers, and negative expression of the CD34 and CD45 markers, as well as for their multilineage differentiation potential (Additional file 1: Fig. S1).

We also evaluated the diameter distribution of purified sEVs from MSCs using Nanosight; we found that the average size of sEVs in the sEV-N, sEVIL-10, and sEV-V groups was close to $100 \mathrm{~nm}$, and the diameter of all sEVs exhibited a relatively narrow size distribution with nearly $90 \%$ of vesicles having a diameter of less than $150 \mathrm{~nm}$ (Fig. 1B). Transmission electron microscopy revealed that the sEVs in the sEV-N, sEV-IL10, and sEV-V groups showed a cup-shaped morphology with a lipid bilayer structure, with the diameters of most sEVs being approximately 80-120 nm (Fig. 1C). Western blotting confirmed that all sEV samples expressed the TSG101 and CD9 tetraspanin markers (Fig. 1D). Successful transfection of the MSCs with lentivirus was initially confirmed $48 \mathrm{~h}$ posttransfection by fluorescence microscopy (Additional file 2: Fig. S2). Real-time PCR revealed that the MSCs transfected with IL-10-expressing lentivirus expressed high levels of $I l-10$ mRNA (Fig. 1E). In addition, sEVs derived from IL-10-overexpressing MSCs expressed

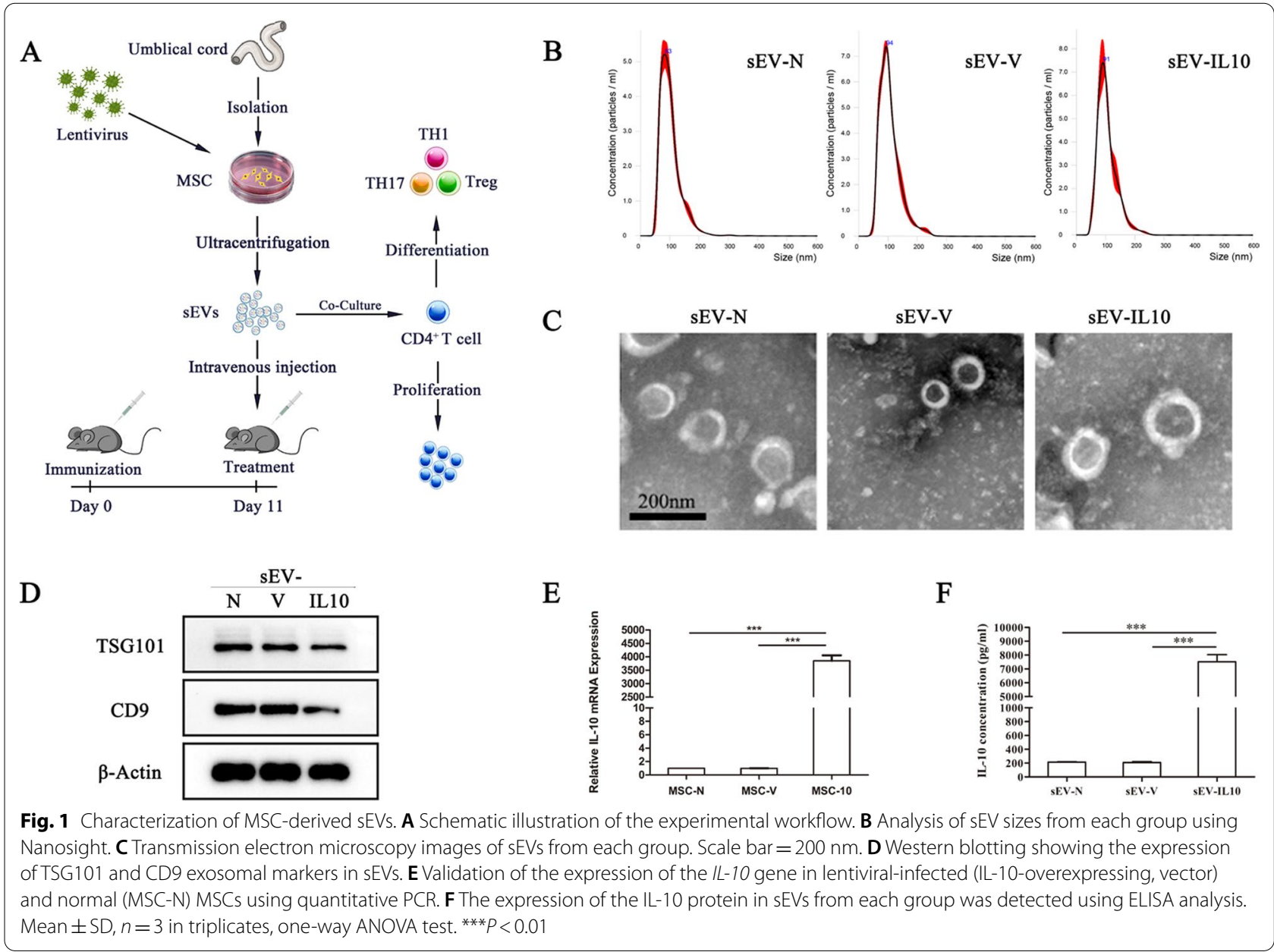


high levels of the IL-10 protein, as indicated by ELISA (Fig. 1F).

\section{Intravenous injection of small extracellular vesicles derived from IL-10-overexpressing MSCs dramatically enhanced the therapeutic effect on experimental autoimmune uveitis}

We first examined the therapeutic effect of recombinant IL-10 in EAU mice. Mice received a single i.v. injection of $500 \mathrm{ng}$ recombinant IL-10 on day 11 post-immunization or five days of consecutive i.v. injections of recombinant IL-10 starting on day 11 post-immunization. We found that only consecutive injection of recombinant IL-10 reduced the severity of EAU, with a significant reduction of clinical scores from day 14 to day 22 postimmunization $(P<0.05)$ (Fig. $2 \mathrm{~A}, \mathrm{~B})$. The histological scores at the peak of EAU (day 18 post-immunization) were in accordance with the clinical scores (Fig. 2C, D).

Next, we compared the therapeutic effects of sEVs in the sEV-N, sEV-IL10, and sEV-V groups on EAU. To this end, we i.v. injected $50 \mu \mathrm{g}$ sEV-N, sEV-IL10, or sEV-V into EAU mice on day 11 post-immunization. We found that the mean clinical score of the sEV-IL10-treated group was significantly lower than other groups from day 14 to day 22 post-immunization $(P<0.01)$ (Fig. $2 \mathrm{E}, \mathrm{F}$ ). We did not observe any significant differences between the $\mathrm{sEV}-\mathrm{N}$ and $\mathrm{sEV}-\mathrm{V}$ groups. We further noticed that the histological scores at the peak of EAU (day 18 postimmunization) were in accordance with the clinical scores (Fig. 2G, H). We specifically observed that mice in the sEV-IL10-treated group showed fewer infiltrating inflammatory cells in the eye, less photoreceptor layer damage, and milder retinal folds than mice in the other groups.

Th1, Th17, and Treg cells play crucial roles in the pathogenesis of EAU. Hence, we examined the T-lymphocyte subsets in the eyes, spleens, and draining lymph nodes (LNs) of mice in each group at the peak of EAU using flow cytometry. We detected that mice in the $\mathrm{sEV}-\mathrm{N}$ and $\mathrm{sEV}-\mathrm{V}$ groups had lower percentages of CD $4+$ IFN- $\gamma+$ and CD4 + IL17 + cells in the eyes, and higher percentages of CD4+FOX3 + cells in the spleen and LNs than the PBS control group. In contrast, we noticed that administration of sEV-IL10 further reduced the infiltration of CD $4+$ IFN- $\gamma+$ and CD $4+$ IL17 + cells in the eyes (Fig. 3A-C), spleen and LNs (Fig. 3D-I), whereas upregulated CD4+FOX3 + cells in the spleen and LNs (Fig. 3G-L).

\section{Small extracellular vesicles were rapidly enriched in target} tissues in vivo and internalized by T-cells in vitro

To observe the distribution of sEVs in target organs, we labeled sEVs with red fluorescence PKH-26, i.v. injected them into naïve and EAU mice, and traced them in vivo. After 24 and $72 \mathrm{~h}$, we collected the eyeballs, spleens, LNs, livers, kidneys, and hearts of mice. We identified PKH26-labeled red sEVs in the eyeballs of EAU mice at $24 \mathrm{~h}$, which were still detected at $72 \mathrm{~h}$, whereas no red fluorescence was observed in the eyes of naïve mice (Fig. 4A). We also detected the presence of red fluorescence in the spleen and LNs of EAU mice, which attenuated over time and was stronger than that in the spleen and LNs of naïve mice (Fig. 4B, C, G). Only a trace level of fluorescence was detected in the livers, kidney and heart of mice (Fig. 4D-F, H).

It has been shown that sEVs function through internalization or binding to cell surface receptors [30]. To study the interaction pattern between sEVs and T-cells, we cocultured T-cells with PKH-26-labeled sEV-N (20 $\mu \mathrm{g}$ / $\mathrm{mL}$ ), and collected cells at 1,3 , and $6 \mathrm{~h}$ to detect red fluorescence. We found the presence of red $\mathrm{PKH}-26$ signal in $\mathrm{CD} 4+\mathrm{T}$-cells at 1,3 , and $6 \mathrm{~h}$, and the fluorescence intensity of the cells increased with incubation time (Fig. 5A, B).

\section{Overexpression of IL10 enhanced the suppressive effect of mesenchymal stem cell-small extracellular vesicles on both the nonspecific proliferation and antigen-specific response of T-cells}

To identify the role of sEV-IL10 in the proliferation of T-cells, we verified the effects of different concentrations $(0,1,10,50$, and $100 \mu \mathrm{g} / \mathrm{mL})$ of $\mathrm{sEV}-\mathrm{N}$ on the proliferation of naive CD4+T-cells. Then, we labeled isolated T-cells from naïve mice with carboxyfluorescein succinimidyl ester (CFSE) and stimulated them with anti-CD3 and anti-CD28 antibodies. We found that sEV-N significantly inhibited the proliferation of CD4+T-cells in a concentration-dependent manner (Fig. 6A, B).

Then, we compared the inhibitory capacity of the $3 \mathrm{sEV}$ groups $(10 \mu \mathrm{g} / \mathrm{mL})$ on the proliferation of CD4+T-cells. We found that sEV-IL10 exhibited the strongest inhibition among the 3 sEVs (Fig. 6C, D).

(See figure on next page.)

Fig. 2 Treatment with sEV-IL10 dramatically enhanced the therapeutic effect of sEV-N. A Mean clinical scores of mice in single injection group and multiple injection group recorded every $2 \mathrm{~d}$ from day 8 to day 22 post-immunization. B Mean clinical scores of mice in single injection group and multiple injection group on day 18 post-immunization. C, D Representative histopathological images and scores in the single injection group and multiple injection group. E Mean clinical scores in the sEV-N-, sEV-IL10-, and sEV-V-treated (50 $\mu \mathrm{g})$ groups recorded every $2 \mathrm{~d}$ from day 8 to day 22 post-immunization. F Mean clinical scores of each sEV-treated group on day 18 post-immunization. G, H Representative histopathological images and scores in the sEV-N-, sEV-IL10-, and sEV-V-treated $(50 \mu \mathrm{g})$ groups. Mean $\pm \mathrm{SD}, n=6$ per group, one-way ANOVA test. ${ }^{* *} P<0.01,{ }^{*} P<0.05$ 
$\mathbf{A}$

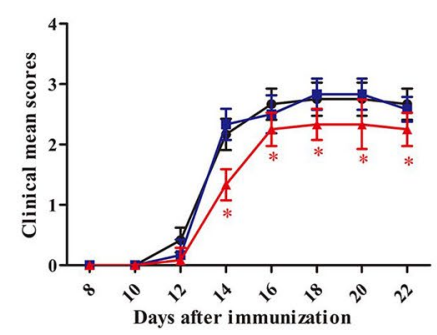

$\rightarrow$ PBS

- Single injection of IL-10

- Multiple injections of IL-10

C

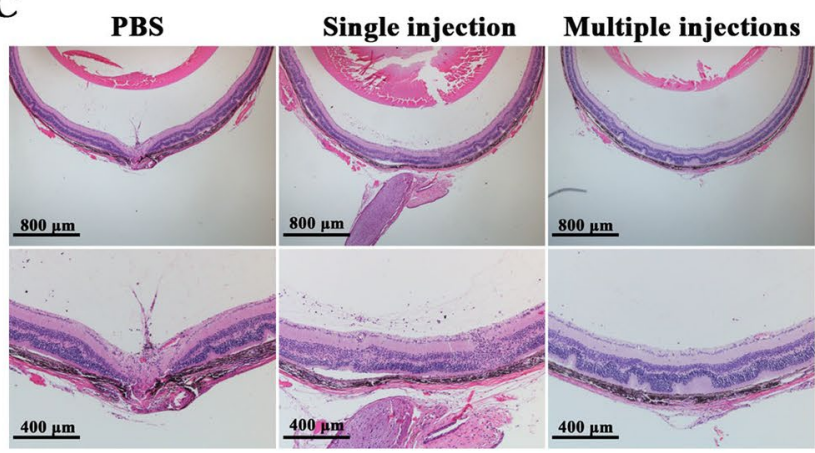

$\mathbf{E}$

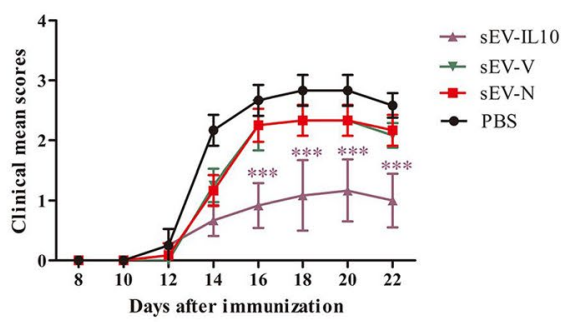

G

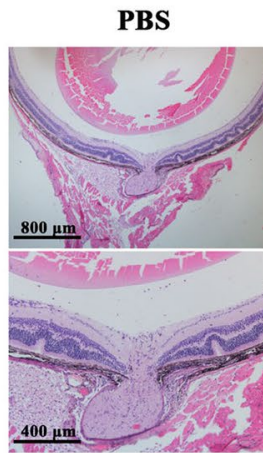

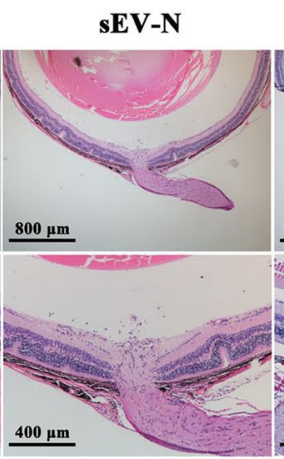

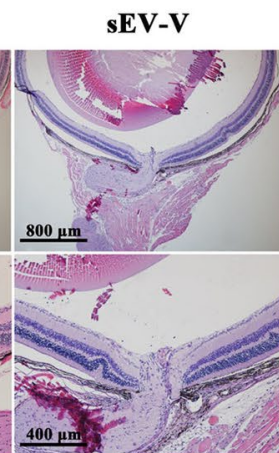

B

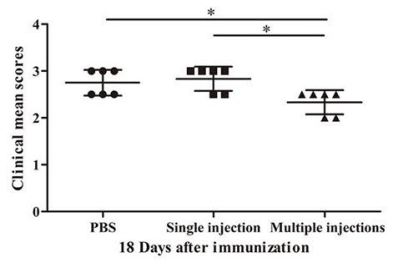

D

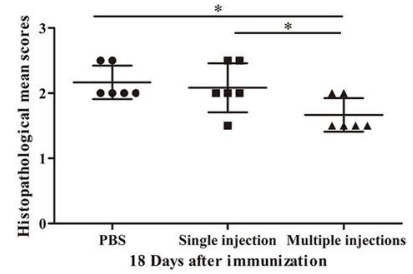

F

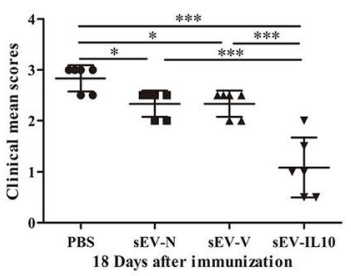

H

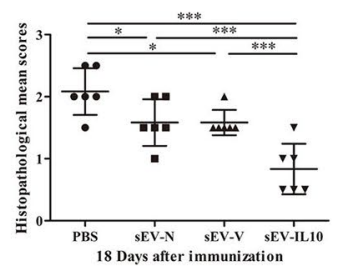

Fig. 2 (See legend on previous page.) 


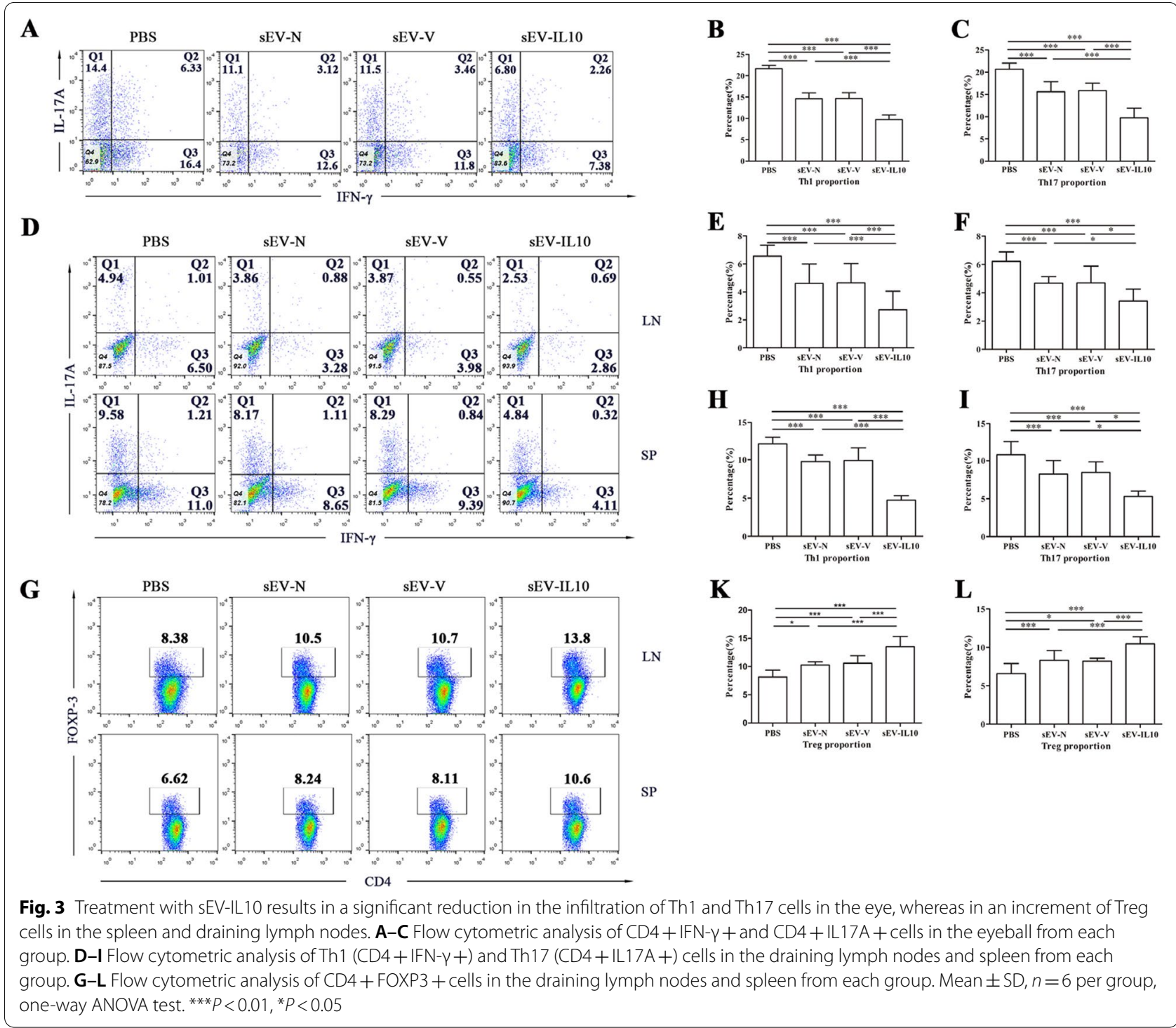

We further assessed the inhibitory capacity of sEVs on the proliferation of IRBP ${ }_{651-670^{-}}$-specific T-cells using the BrdU kit. We isolated T-cells from the spleen and LNs of EAU mice (day 14 post-immunization) and then stimulated them with increasing doses of IRBP ${ }_{651-670}$. As shown in Fig. 6E, sEV-IL10 significantly inhibited the proliferation of IRBP651-670 specific T-cells $(P<0.05)$. Whereas, we found that the sEV-N and sEV-V groups showed significant inhibitory effects only at $20 \mu \mathrm{g} / \mathrm{mL} \operatorname{IRBP}_{651-670}(P<0.05)$. To compare IRBP $_{651-670}$ specific Th1 and Th17 responses, the cell culture supernatants (with $20 \mu \mathrm{g} / \mathrm{mL} \mathrm{IRBP}_{651-670}$ ) were collected and levels of IFN- $\gamma$ and IL-17A were measured. As shown in Fig. 6G, F, the levels of IFN- $\gamma$ and IL-17A were significantly lower in culture supernatants of sEV-IL10 treated T cells $(P<0.01)$. Our results indicated that IL-10-overexpressing sEVs greatly enhanced the suppressive effect of sEVs on both nonspecific and antigen-specific $\mathrm{T}$-cell responses and Th1 and Th17 differentiation.

\section{Overexpression of IL10 enhanced the suppressive effect of mesenchymal stem cell-small extracellular vesicles on the differentiation of Th1 and Th17 cells and upregulated Treg cells in vitro}

We further investigated the effect of sEV-IL10 on the T-cells differentiation. We isolated CD4+ T-cells from the spleen of naïve mice using a magnetic bead negative selection kit and incubated them with $10 \mu \mathrm{g} /$ 

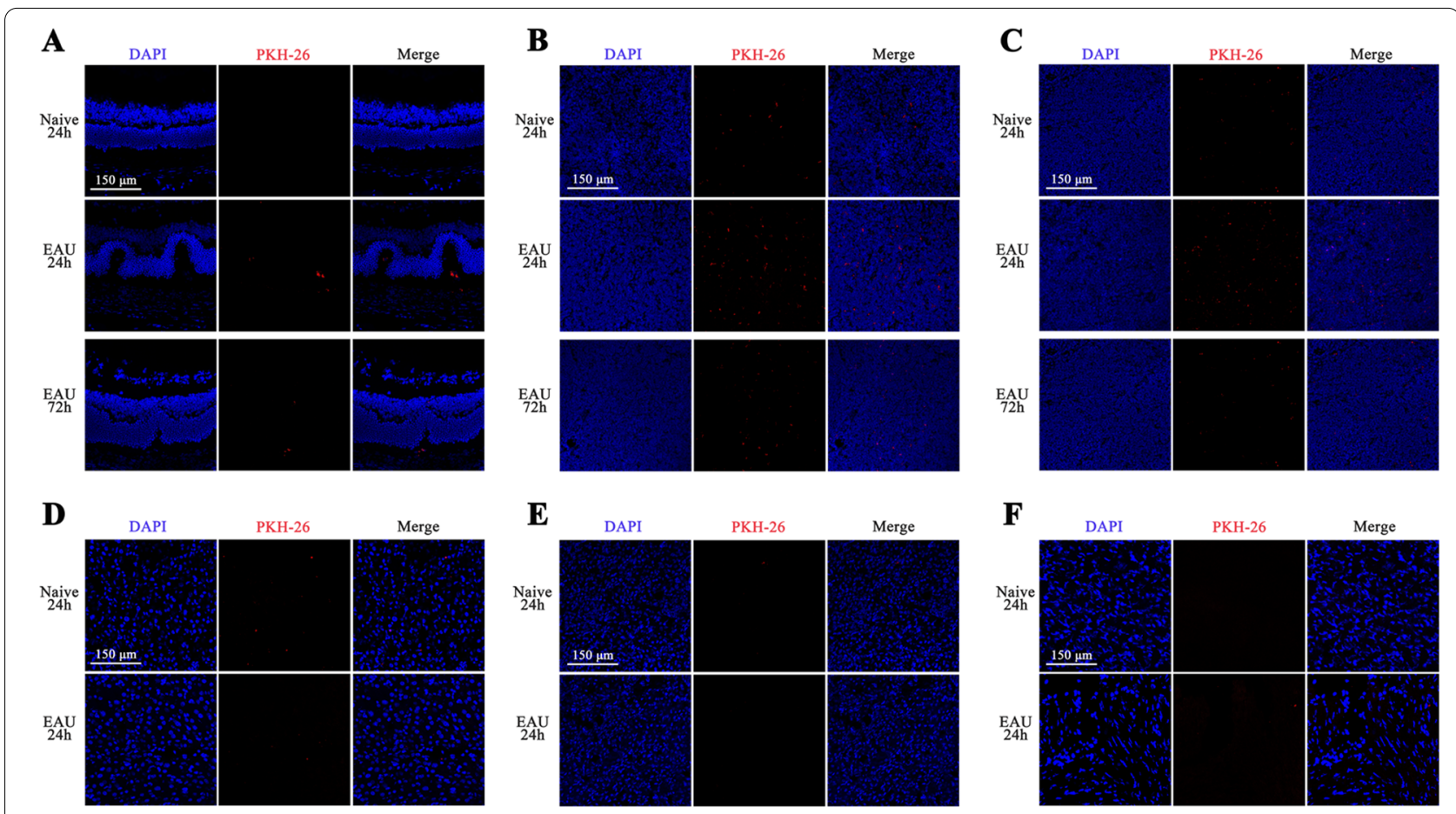

G

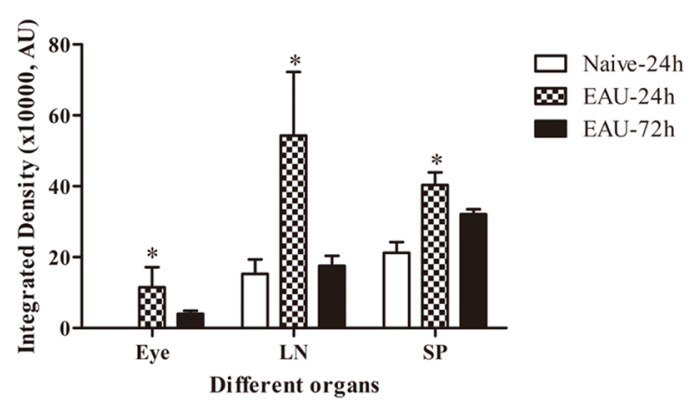

$\mathbf{H}$

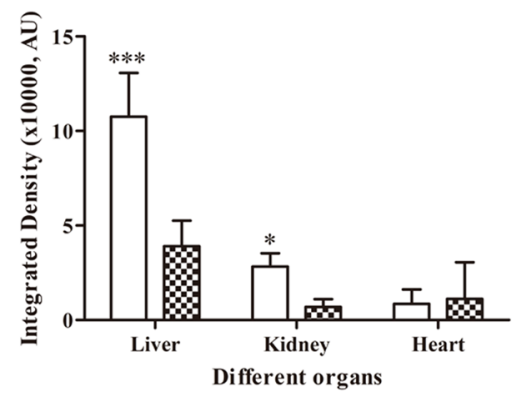

Fig. 4 The in vivo distribution of intravenously injected sEVs in different organs in EAU and naive mice was examined using confocal microscopy. A Representative confocal images of PKH-26 immunofluorescence in the eyeballs of EAU and naive mice, which were i.v. injected with sEV-N (100 $\mu \mathrm{g}$ ) 24 or $72 \mathrm{~h}$ prior. B, C. Representative confocal images of PKH-26 immunofluorescence in the lymph nodes and spleen of EAU and naive mice, which were i.v. injected with sEV-N $(100 \mu \mathrm{g}) 24$ or $72 \mathrm{~h}$ prior. D-F Representative confocal images of PKH-26 immunofluorescence in the liver, kidney, and hearts of EAU and naive mice, which were i.v. injected with sEV-N $(100 \mu \mathrm{g}) 24 \mathrm{~h}$ prior. G-H. The fluorescence intensity was measured by integrated density using ImageJ software. Scale bar $=150 \mu \mathrm{m}$. Mean $\pm S D, n=3$ per group, one-way ANOVA test. ${ }^{* * *} P<0.01,{ }^{*} P<0.05$

mL sEVs under Th1, Th17, and Treg cell differentiation conditions. After $5 \mathrm{~d}$ of culture, we evaluated cell differentiation using flow cytometry. We specifically observed that sEV-N and sEV-V inhibited the differentiation of both CD4+IFN- $\gamma+$ and $\mathrm{CD} 4+\mathrm{IL}-$ $17 \mathrm{~A}+$ cells, while sEV-IL10 greatly enhanced the inhibitory effect of MSC-sEVs $(P<0.05)$ (Fig. 7A-D). We also found that under Treg cell differentiation conditions, sEV-IL10 upregulated the percentage of Fox $3+$ cells $(P<0.05)$, whereas sEV-N and sEV-V had no effect (Fig. 7E, F). These results indicated that the overexpression of IL-10 enhanced the immunosuppressive effect of sEVs on EAU by inhibiting the responses of both Th1 and Th17 cells and promoting the responses of Treg cells.

\section{Discussion}

In this study, we established IL-10-overexpressing MSCs by transfecting them with a lentivirus carrying the $I l-10$ gene and then obtained their sEVs, which contained high levels 


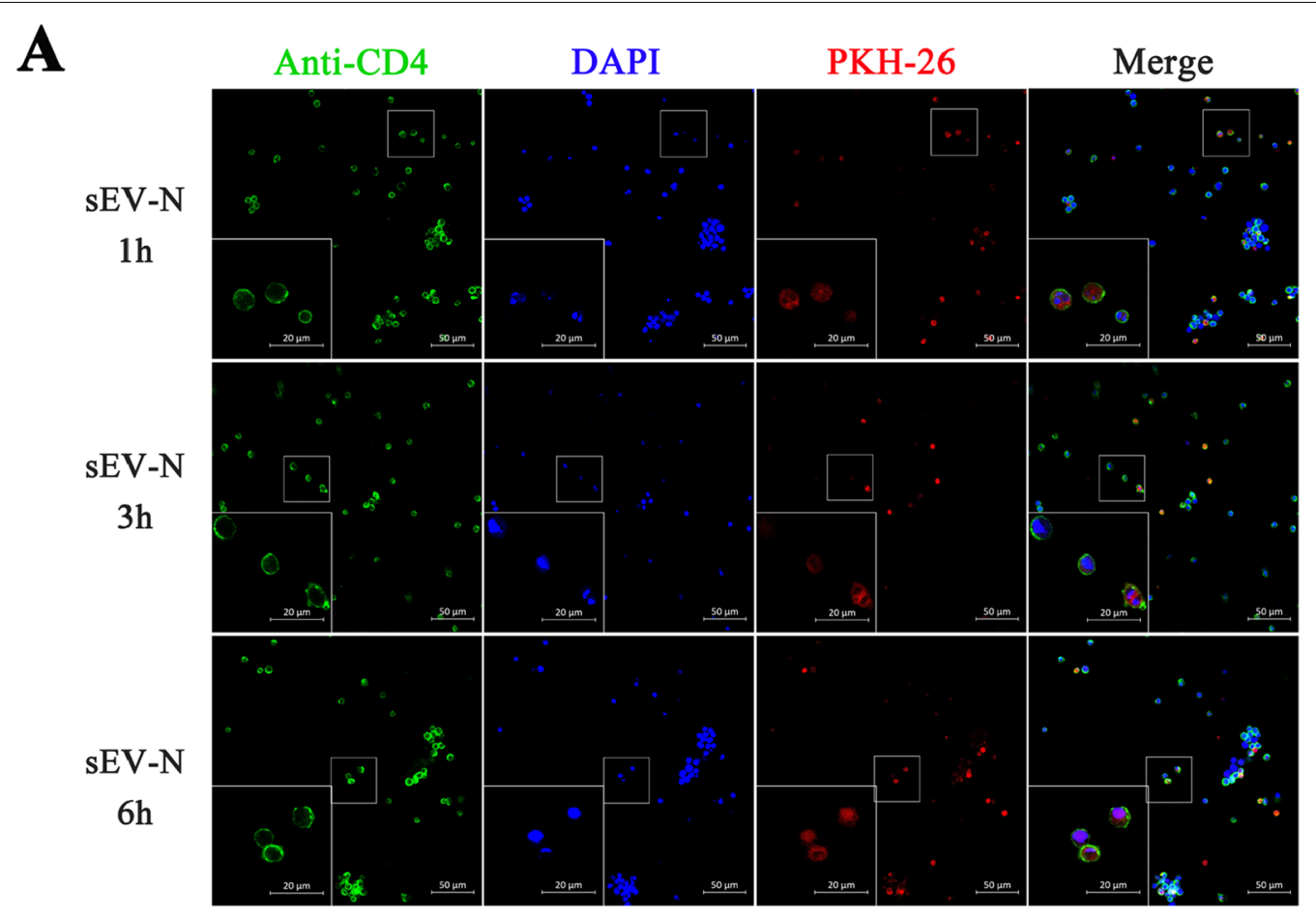

B

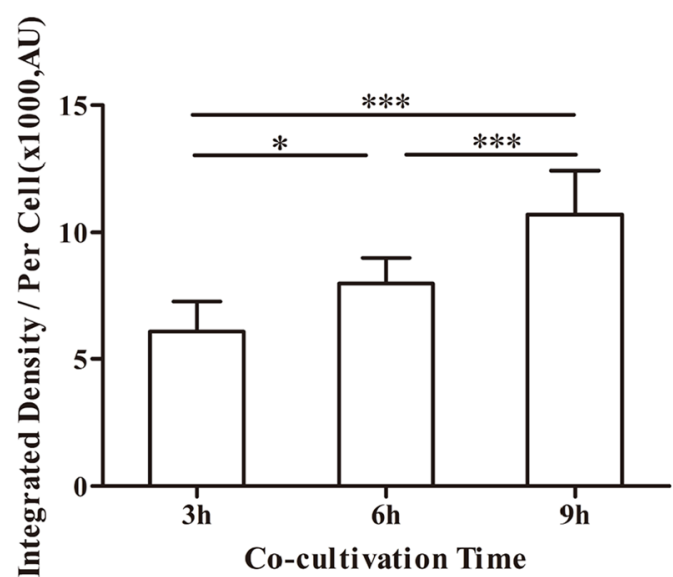

Fig. 5 The distribution of sEVs, when cocultured with CD4+T-cells for 1, 3, and $6 \mathrm{~h}$ in vitro at concentrations of $20 \mu \mathrm{g} / \mathrm{ml}$. A Representative confocal images of PKH-26 immunofluorescence on the CD4 + cell. B The fluorescence intensity was measured by integrated density using Image J software. The mean integrated density of per cell increased significantly with incubation time. Mean $\pm S D, n=3$ per group, one-way ANOVA test. ${ }^{* *} P<0.01,{ }^{*} P<0.05$

of IL-10 (sEV-IL10). These IL-10-overexpressing sEVs demonstrated long-lasting therapeutic effects on EAU compared with normal MSC-sEVs, which express low levels of IL-10. In vitro experiments revealed that overexpression of IL-10 greatly enhanced the suppressive effect of normal MSC-sEVs on the proliferation of T-cells and responses of Th1/Th17 cells, whereas upregulated Treg cells.
MSC-EVs have been reported to regulate the activation, proliferation, differentiation, maturation, and migration of various immune cells, exhibiting therapeutic potential in animal models of various immune-related diseases, such as inflammatory bowel disease (IBD), graft-versushost disease (GVHD), collagen-induced arthritis (CIA), and autoimmune uveitis [24, 31-36]. MSC-EVs express 


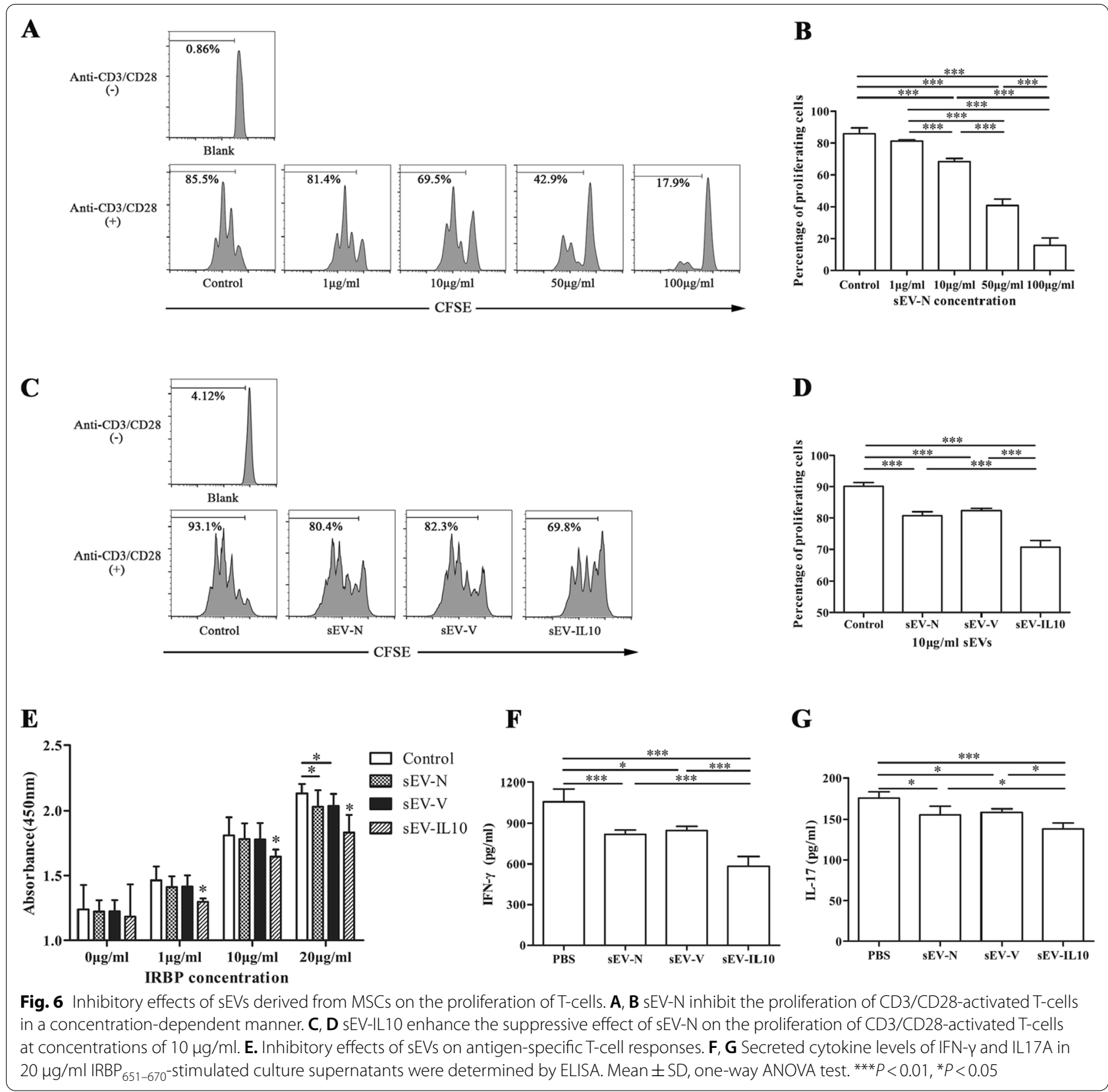

several adhesion molecules, such as CD29, CD73, and CD44, which enable them to access the inflammatory and injury sites [37, 38], and transfer their contents to target cells to alter cell functions. We previously demonstrated that periocular injection of MSC-sEVs on established EAU attenuated disease progression in a rat model of EAU. However, the therapeutic effect was weak and multiple injections of MSC-sEVs were required [24]. Shigemoto-Kuroda et al. reported that preventive i.v. injection of $30 \mu \mathrm{g} \mathrm{sEVs}$ derived from human bone marrow MSCs at the same time of disease induction alleviated the progression of EAU [36]. However, in the clinical practice, patients usually visit to hospital after clinical symptoms occur and the therapeutic effect of sEVs on ongoing disease needs verified. Thus, using the current forms of MSC-sEVs to treat patients with uveitis or other autoimmune diseases is far from ideal. Therefore, improving the treatment efficacy of MSC-sEVs by reprogramming the encapsulated components of the vesicles is necessary for their potential clinical translation.

IL-10 is a well-known cytokine possessing a strong immunosuppressive effect; however, its use as an 


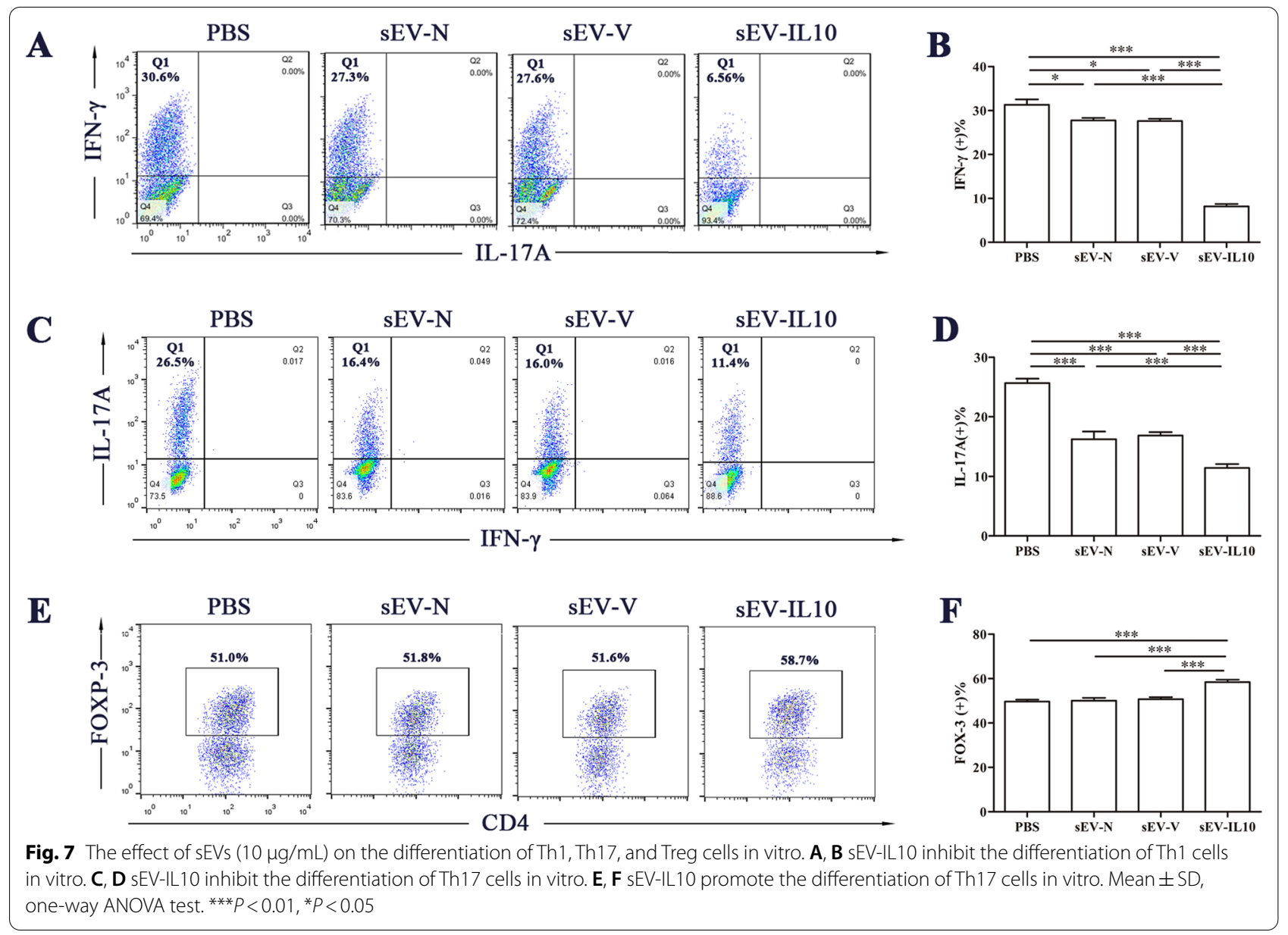

immunosuppressant for treating autoimmune diseases in the clinical settings has been limited by its short terminal half-life (approximately $2.7-4.5 \mathrm{~h}$ ) [39] and rapid clearance in vivo. Due to their nanoscale size and long half-life, sEVs can be efficiently used as drug carriers [40-42]. The nanotoxicity and rapid drug clearance by living immune system limits the widespread application of nano-delivery systems and polyethyleneglycol (PEG) $[43,44]$. In contrast, sEVs derived from the body have better biocompatibility and lower immunogenicity, and it was shown that their immune privileged status that can efficiently reduce drug clearance[45-47]. In addition, sEVs have the ability to cross biological barriers, such as the blood-brain and blood-ocular barriers [48-50]. Moreover, the lipid bilayer membrane of sEVs can protect the encysted proteins and miRNAs from degradation, thereby preserving their bioactivity for a long time $[20,51]$. Our studies incorporating IL-10 into sEVs of MSCs enhanced the advantages of both IL-10 and sEVs of MSCs in the inhibition of immune suppression in autoimmune diseases. Compared with normal
sEVs from MSCs, IL-10-overexpressing MSC-sEVs significantly inhibited EAU after a single i.v. injection at disease onset. These results indicated that MSC-sEVs carrying high concentrations of IL-10 possess strong and long-lasting immunosuppressive effects and are ideal cell-free candidates for treating autoimmune uveitis and potentially other autoimmune diseases.

As previously mentioned, due to their immunosuppressive effects, MSC-sEVs have been used for the inhibition of autoimmune responses. MSC-sEVs have been reported to reduce the differentiation of Th1 cells and production of IFN- $\gamma$ by modulating the miRNA profile in Th1 cells in vitro and promoting the shift from Th1 to Th2 cells [52]. MSC-sEVs have also been shown to modulate the Th17/ Treg balance by inhibiting the differentiation of Th17 cells and expression of IL-17 [53-55]. However, the role of MSC-sEVs in the proliferation of T-cells in vitro has been controversial. Studies by Chen and Andrade revealed that MSC-sEVs failed to suppress the proliferation of T-cells in vitro [56, 57], whereas others showed the opposite results [58-60]. Our in vitro results demonstrated that 
normal MSC-sEVs inhibited the proliferation of T-cells in a concentration-dependent manner and suppressed the differentiation of Th1 and Th17 cells. Moreover, we found that the IL-10-overexpressing MSC-sEVs exhibited superior advantages in inhibiting the proliferation of T-cells and differentiation of Th1 and Th17 cells, whereas upregulated the differentiation of Treg cells over normal sEVs. These results demonstrated a synergistic suppressive effect of both MSC-sEVs and IL-10 on the proliferation of T-cells and differentiation of Th1/Th17/Treg cells.

We also detected the presence of MSC-sEVs in the eyes and lymphoid tissues of EAU mice, in consistency with studies reporting that sEVs can cross the biological barrier [48] and MSC-sEVs possess chemotactic effects in diseased, but not naïve organs. For instance, Riazifar et al. detected the fluorescent signal of MSCsEVs in the spinal cords of EAU but not WT mice [61]. Mao et al. found that only the colon tissues of IBD mice injected with indocyanine green labeled MSC-sEVs showed strong fluorescence [62]. It has been known that sEVs interact with target cells via various routes, such as internalization, binding to receptors on cell surface, and fusing with cell membrane $[63,64]$. We found that sEVs were translocated in the cytoplasm of T-cells when cocultured in vitro, indicating that sEVs might exert their immunoregulatory effect directly on T-cells.

\section{Conclusions}

In summary, our study demonstrated that sEVs derived from IL-10-overexpressing MSCs have notable effects on alleviating EAU development in mice. Thus, MSC-sEVs with high expression of IL-10 might be a novel approach for the treatment of autoimmune uveitis or other autoimmune diseases in human.

\begin{abstract}
Abbreviations
sEVs: Small extracellular vesicles; MSCs: Mesenchymal stem cells; SEV-IL10: IL-10-overexpressing MSC-sEVs; EAU: Experimental autoimmune uveitis; LN: Lymph nodes; TNF-a: Anti-tumor necrosis factor-a; MSC-sEVs: MSCderived sEVs; IL-10: Interleukin 10; ARVO: Association for research in vision and ophthalmology; TMUEC: Tianjin Medical University Eye Hospital; SPF: Specific pathogen-free; HEK-293 T: Human embryonic kidney 293 T cells; MOI: Multiplicity of infection; IFA: Incomplete Freund's adjuvant; PTX: Pertussis toxin; sEV-N: Normal MSC-sEVs; sEV-V: Vector-infected MSC-sEVs; H\&E: Hematoxylin and eosin; OCT: Optimal cutting temperature; i.v: Intravenous injection; LNs: Lymph nodes; CFSE: Carboxyfluorescein succinimidyl ester; IBD: Inflammatory bowel disease; CIA: Collagen-induced arthritis; GVHD: Graft-versus-host disease.
\end{abstract}

\section{Supplementary Information}

The online version contains supplementary material available at https://doi. org/10.1186/s13287-022-02780-9.

Additional file 1: Figure S1. MSCs phenotype and differentiation capacity identification. A Positive expression of the CD29, and CD90 markers, and negative expression of the CD34 and CD45 markers. B Multilineage differentiation potential of MSCs.

Additional file 2: Figure S2. The bright field and GFP fluorescence photographs of MSC transduced with lentivirus.

\section{Acknowledgements}

Not applicable.

\section{Authors' contributions}

YTL was involved in the conceptualization, methodology, validation formal analysis and writing - original draft. XJR contributed to the conceptualization, methodology, validation and formal analysis. ZHZ contributed to the methodology, validation and formal analysis. YND was involved in the validation and investigation. HL contributed to the validation and investigation. SC contributed to the validation and software. HS helped in the methodology and writing - review and editing. XRL was involved in the writing - review and editing. XMZ contributed to the conceptualization, methodology, writing-review and editing, supervision and funding acquisition. All authors have read and approved the manuscript.

\section{Funding}

This research was supported by grants from the National Natural Science Foundation of China (81870651, 81600723), Tianjin Municipal Science and Technology Commission (20YFZCSY00990, 20JCZDJC00100) and Tianjin Key Medical Discipline (Specialty) Constrution Project.

\section{Availability of data and materials}

The datasets used or analyzed during the current study are available from the corresponding author on reasonable request.

\section{Declarations}

\section{Ethics approval and consent to participate}

The animal studies were approved by the Laboratory Animal Care and Use Committee of Tianjin Medical University Eye Hospital (TMUEC) (No. TJYY2019103022).

\section{Consent for publication}

Not applicable.

\section{Competing interests}

The authors have declared that no competing interest exists.

\section{Author details}

${ }^{1}$ Tianjin Key Laboratory of Retinal Functions and Diseases, Tianjin Branch of National Clinical Research Center for Ocular Disease, Eye Institute and School of Optometry, Tianjin Medical University Eye Hospital, Tianjin, China. ${ }^{2}$ Department of Ophthalmology and Visual Sciences, Kentucky Lions Eye Center, University of Louisville, School of Medicine, Louisville, KY, USA.

Received: 11 November 2021 Accepted: 16 February 2022

Published online: 07 March 2022

References

1. Krishna U, Ajanaku D, Denniston AK, Gkika T. Uveitis: a sightthreatening disease which can impact all systems. Postgrad Med J. 2017;93(1106):766-73.

2. Nicolela Susanna F, Pavesio C. A review of ocular adverse events of biological anti-TNF drugs. J Ophthalmic Inflamm Infect. 2020;10(1):11.

3. Touhami S, Diwo E, Seve P, Trad S, Bielefeld P, Sene D, et al. Expert opinion on the use of biological therapy in non-infectious uveitis. Expert Opin Biol Ther. 2019;19(5):477-90.

4. Oh JY, Lee RH. Mesenchymal stromal cells for the treatment of ocular autoimmune diseases. Prog Retin Eye Res. 2021;85:100967. 
5. Yang C, Wu M, You M, Chen Y, Luo M, Chen Q. The therapeutic applications of mesenchymal stromal cells from human perinatal tissues in autoimmune diseases. Stem Cell Res Ther. 2021;12(1):103.

6. Zhang X, Ren X, Li G, Jiao C, Zhang L, Zhao S, et al. Mesenchymal stem cells ameliorate experimental autoimmune uveoretinitis by comprehensive modulation of systemic autoimmunity. Invest Ophthalmol Vis Sci. 2011;52(6):3143-52.

7. Ko JH, Lee HJ, Jeong HJ, Kim MK, Wee WR, Yoon SO, et al. Mesenchymal stem/stromal cells precondition lung monocytes/macrophages to produce tolerance against allo- and autoimmunity in the eye. Proc Natl Acad Sci USA. 2016;113(1):158-63.

8. Dong L, Chen X, Shao H, Bai L, Li X, Zhang X. Mesenchymal stem cells inhibited dendritic cells via the regulation of STAT1 and STAT6 phosphorylation in experimental autoimmune uveitis. Curr Mol Med. 2018;17(7):478-87.

9. Tasso R, llengo C, Quarto R, Cancedda R, Caspi RR, Pennesi G. Mesenchymal stem cells induce functionally active T-regulatory lymphocytes in a paracrine fashion and ameliorate experimental autoimmune uveitis. Invest Ophthalmol Vis Sci. 2012;53(2):786-93.

10. Ko JH, Lee HJ, Jeong HJ, Oh JY. Ly6C(hi) monocytes are required for mesenchymal stem/stromal cell-induced immune tolerance in mice with experimental autoimmune uveitis. Biochem Biophys Res Commun. 2017:494(1-2):6-12.

11. Qin Y, Chan AM, Chang YL, Matynia A, Kouris NA, Kimbrel EA, et al. Human embryonic stem cell-derived mesenchymal stromal cells decrease the development of severe experimental autoimmune uveitis in B10.RIII mice. Ocul Immunol Inflamm. 2018;26(8):1228-36.

12. Eggenhofer E, Benseler V, Kroemer A, Popp FC, Geissler EK, Schlitt HJ, et al. Mesenchymal stem cells are short-lived and do not migrate beyond the lungs after intravenous infusion. Front Immunol. 2012;3:297.

13. Toma C, Pittenger MF, Cahill KS, Byrne BJ, Kessler PD. Human mesenchymal stem cells differentiate to a cardiomyocyte phenotype in the adult murine heart. Circulation. 2002;105(1):93-8.

14. Dlouhy BJ, Awe O, Rao RC, Kirby PA, Hitchon PW. Autograft-derived spinal cord mass following olfactory mucosal cell transplantation in a spinal cord injury patient: case report. J Neurosurg Spine. 2014;21(4):618-22.

15. Vulliet PR, Greeley M, Halloran SM, MacDonald KA, Kittleson MD. Intracoronary arterial injection of mesenchymal stromal cells and microinfarction in dogs. Lancet. 2004;363(9411):783-4.

16. Thery C, Witwer KW, Aikawa E, Alcaraz MJ, Anderson JD, Andriantsitohaina $R$, et al. Minimal information for studies of extracellular vesicles 2018 (MISEV2018): a position statement of the International Society for Extracellular Vesicles and update of the MISEV2014 guidelines. J Extracell Vesicles. 2018;7(1):1535750.

17. Gnecchi M, Danieli P, Malpasso G, Ciuffreda MC. Paracrine mechanisms of mesenchymal stem cells in tissue repair. Methods Mol Biol. 2016;1416:123-46.

18. Zhou Y, Yamamoto $Y$, Xiao Z, Ochiya T. The immunomodulatory functions of mesenchymal stromal/stem cells mediated via paracrine activity. J Clin Med. 2019;8(7):1025.

19. Zhang B, Yin Y, Lai RC, Tan SS, Choo AB, Lim SK. Mesenchymal stem cells secrete immunologically active exosomes. Stem Cells Dev. 2014;23(11):1233-44.

20. Ge Q, Zhou Y, Lu J, Bai Y, Xie X, Lu Z. miRNA in plasma exosome is stable under different storage conditions. Molecules. 2014;19(2):1568-75.

21. Chinnappan M, Srivastava A, Amreddy N, Razaq M, Pareek V, Ahmed R, et al. Exosomes as drug delivery vehicle and contributor of resistance to anticancer drugs. Cancer Lett. 2020;486:18-28.

22. Faroogi AA, Desai NN, Qureshi MZ, Librelotto DRN, Gasparri ML, Bishayee $A$, et al. Exosome biogenesis, bioactivities and functions as new delivery systems of natural compounds. Biotechnol Adv. 2018;36(1):328-34.

23. Ren K. Exosomes in perspective: a potential surrogate for stem cell therapy. Odontology. 2019;107(3):271-84.

24. Bai L, Shao H, Wang H, Zhang Z, Su C, Dong L, et al. Effects of mesenchymal stem cell-derived exosomes on experimental autoimmune uveitis. Sci Rep. 2017;7(1):4323.

25. Nasef A, Chapel A, Mazurier C, Bouchet S, Lopez M, Mathieu N, et al. Identification of IL-10 and TGF-beta transcripts involved in the inhibition of T-lymphocyte proliferation during cell contact with human mesenchymal stem cells. Gene Expr. 2007;13(4-5):217-26.
26. Rizzo LV, Xu H, Chan CC, Wiggert B, Caspi RR. IL-10 has a protective role in experimental autoimmune uveoretinitis. Int Immunol. 1998;10(6):807-14.

27. Jian $R$, Yang M, Xu F. Lentiviral-mediated silencing of mast cell-expressed membrane protein 1 promotes angiogenesis of rats with cerebral ischemic stroke. J Cell Biochem. 2019;120(10):16786-97.

28. Livak KJ, Schmittgen TD. Analysis of relative gene expression data using real-time quantitative PCR and the 2(-Delta Delta C(T)) Method. Methods. 2001;25(4):402-8.

29. Agarwal RK, Silver PB, Caspi RR. Rodent models of experimental autoimmune uveitis. Methods Mol Biol. 2012;900:443-69.

30. Gonda A, Kabagwira J, Senthil GN, Wall NR. Internalization of exosomes through receptor-mediated endocytosis. Mol Cancer Res. 2019;17(2):337-47.

31. Gowen A, Shahjin F, Chand S, Odegaard KE, Yelamanchili SV. Mesenchymal stem cell-derived extracellular vesicles: challenges in clinical applications. Front Cell Dev Biol. 2020;8:149.

32. Zhao AG, Shah K, Cromer B, Sumer H. Mesenchymal stem cell-derived extracellular vesicles and their therapeutic potential. Stem Cells Int. 2020;2020:8825771

33. LiY, Altemus J, Lightner AL. Mesenchymal stem cells and acellular products attenuate murine induced colitis. Stem Cell Res Ther. 2020;11(1):515.

34. Fujii S, Miura Y, Fujishiro A, Shindo T, Shimazu Y, Hirai H, et al. Graft-versushost disease amelioration by human bone marrow mesenchymal stro$\mathrm{mal} / \mathrm{stem}$ cell-derived extracellular vesicles is associated with peripheral preservation of Naive T cell populations. Stem Cells. 2018;36(3):434-45.

35. Cosenza S, Toupet K, Maumus M, Luz-Crawford P, Blanc-Brude O, Jorgensen C, et al. Mesenchymal stem cells-derived exosomes are more immunosuppressive than microparticles in inflammatory arthritis. Theranostics. 2018;8(5):1399-410.

36. Shigemoto-Kuroda T, Oh JY, Kim DK, Jeong HJ, Park SY, Lee HJ, et al. MSC-derived extracellular vesicles attenuate immune responses in two autoimmune murine models: type 1 diabetes and uveoretinitis. Stem Cell Reports. 2017:8(5):1214-25.

37. Otero-Ortega L, de Frutos MCG, Laso-Garcia F, Rodriguez-Frutos B, Medina-Gutierrez E, Lopez JA, et al. Exosomes promote restoration after an experimental animal model of intracerebral hemorrhage. J Cereb Blood Flow Metab. 2018;38(5):767-79.

38. Grange C, Tapparo M, Bruno S, Chatterjee D, Quesenberry PJ, Tetta C, et al. Biodistribution of mesenchymal stem cell-derived extracellular vesicles in a model of acute kidney injury monitored by optical imaging. Int J Mol Med. 2014;33(5):1055-63.

39. Huhn RD, Radwanski E, Gallo J, Affrime MB, Sabo R, Gonyo G, et al. Pharmacodynamics of subcutaneous recombinant human interleukin-10 in healthy volunteers. Clin Pharmacol Ther. 1997;62(2):171-80.

40. de Jong OG, Kooijmans SAA, Murphy DE, Jiang L, Evers MJW, Sluijter JPG, et al. Drug delivery with extracellular vesicles: from imagination to innovation. Acc Chem Res. 2019;52(7):1761-70.

41. Elsharkasy OM, Nordin JZ, Hagey DW, de Jong OG, Schiffelers RM, Andaloussi SE, et al. Extracellular vesicles as drug delivery systems: Why and how? Adv Drug Deliv Rev. 2020;159:332-43.

42. Syn NL, Wang L, Chow EK, Lim CT, Goh BC. Exosomes in cancer nanomedicine and immunotherapy: prospects and challenges. Trends Biotechnol. 2017:35(7):665-76.

43. Peng $Q$, Zhang $S$, Yang $Q$, Zhang T, Wei $X Q$, Jiang $L$, et al. Preformed albumin corona, a protective coating for nanoparticles based drug delivery system. Biomaterials. 2013;34(33):8521-30.

44. Ishida T, Kashima S, Kiwada H. The contribution of phagocytic activity of liver macrophages to the accelerated blood clearance (ABC) phenomenon of PEGylated liposomes in rats. J Control Release. 2008;126(2):162-5.

45. Johnsen KB, Gudbergsson JM, Skov MN, Pilgaard L, Moos T, Duroux M. A comprehensive overview of exosomes as drug delivery vehiclesendogenous nanocarriers for targeted cancer therapy. Biochim Biophys Acta. 2014;1846(1):75-87.

46. Haney MJ, Klyachko NL, Zhao Y, Gupta R, Plotnikova EG, He Z, et al. Exosomes as drug delivery vehicles for Parkinson's disease therapy. J Control Release. 2015;207:18-30.

47. Zhang Y, Bi J, Huang J, Tang Y, Du S, Li P. Exosome: a review of its classification, isolation techniques, storage, diagnostic and targeted therapy applications. Int J Nanomed. 2020;15:6917-34. 
48. Alvarez-Erviti L, Seow Y, Yin H, Betts C, Lakhal S, Wood MJ. Delivery of siRNA to the mouse brain by systemic injection of targeted exosomes. Nat Biotechnol. 2011;29(4):341-5.

49. Yu B, Shao H, Su C, Jiang Y, Chen X, Bai L, et al. Exosomes derived from MSCs ameliorate retinal laser injury partially by inhibition of MCP-1. Sci Rep. 2016;6:34562.

50. Das CK, Jena BC, Banerjee I, Das S, Parekh A, Bhutia SK, et al. Exosome as a novel shuttle for delivery of therapeutics across biological barriers. Mol Pharm. 2019;16(1):24-40.

51. Valadi H, Ekstrom K, Bossios A, Sjostrand M, Lee JJ, Lotvall JO. Exosomemediated transfer of mRNAs and microRNAs is a novel mechanism of genetic exchange between cells. Nat Cell Biol. 2007;9(6):654-9.

52. Guo L, Lai P, Wang Y, Huang $T$, Chen $X$, Luo C, et al. Extracellular vesicles from mesenchymal stem cells prevent contact hypersensitivity through the suppression of Tc1 and Th1 cells and expansion of regulatory T cells. Int Immunopharmacol. 2019;74:105663.

53. Nojehdehi S, Soudi S, Hesampour A, Rasouli S, Soleimani M, Hashemi SM. Immunomodulatory effects of mesenchymal stem cell-derived exosomes on experimental type-1 autoimmune diabetes. J Cell Biochem. 2018;119(11):9433-43

54. Webb RL, Kaiser EE, Scoville SL, Thompson TA, Fatima S, Pandya C, et al. Human neural stem cell extracellular vesicles improve tissue and functional recovery in the murine thromboembolic stroke model. Transl Stroke Res. 2018;9(5):530-9.

55. Favaro E, Carpanetto A, Caorsi C, Giovarelli M, Angelini C, Cavallo-Perin P, et al. Human mesenchymal stem cells and derived extracellular vesicles induce regulatory dendritic cells in type 1 diabetic patients. Diabetologia. 2016;59(2):325-33.

56. Chen W, Huang Y, Han J, Yu L, Li Y, Lu Z, et al. Immunomodulatory effects of mesenchymal stromal cells-derived exosome. Immunol Res. 2016;64(4):831-40.

57. de Andrade AVG, Bertolino G, Riewaldt J, Bieback K, Karbanova J, Odendahl M, et al. Extracellular vesicles secreted by bone marrow- and adipose tissue-derived mesenchymal stromal cells fail to suppress lymphocyte proliferation. Stem Cells Dev. 2015;24(11):1374-6.

58. Crain SK, Robinson SR, Thane KE, Davis AM, Meola DM, Barton BA, et al. Extracellular vesicles from Wharton's jelly mesenchymal stem cells suppress CD4 expressing T cells through transforming growth factor beta and adenosine signaling in a canine model. Stem Cells Dev. 2019;28(3):212-26.

59. Blazquez R, Sanchez-Margallo FM, de la Rosa O, Dalemans W, Alvarez $V$, Tarazona $R$, et al. Immunomodulatory potential of human adipose mesenchymal stem cells derived exosomes on in vitro stimulated T cells. Front Immunol. 2014;5:556.

60. Monguio-Tortajada M, Roura S, Galvez-Monton C, Pujal JM, Aran G, Sanjurjo L, et al. Nanosized UCMSC-derived extracellular vesicles but not conditioned medium exclusively inhibit the inflammatory response of stimulated T cells: implications for nanomedicine. Theranostics. 2017;7(2):270-84.

61. Riazifar M, Mohammadi MR, Pone EJ, Yeri A, Lasser C, Segaliny Al, et al. Stem cell-derived exosomes as nanotherapeutics for autoimmune and neurodegenerative disorders. ACS Nano. 2019;13(6):6670-88.

62. Mao F, Wu Y, Tang $X$, Kang J, Zhang B, Yan $Y$, et al. Exosomes derived from human umbilical cord mesenchymal stem cells relieve inflammatory bowel disease in mice. Biomed Res Int. 2017;2017:5356760.

63. Kahroba H, Hejazi MS, Samadi N. Exosomes: from carcinogenesis and metastasis to diagnosis and treatment of gastric cancer. Cell Mol Life Sci. 2019;76(9):1747-58

64. van Niel G, D'Angelo G, Raposo G. Shedding light on the cell biology of extracellular vesicles. Nat Rev Mol Cell Biol. 2018:19(4):213-28.

\section{Publisher's Note}

Springer Nature remains neutral with regard to jurisdictional claims in published maps and institutional affiliations.

Ready to submit your research? Choose BMC and benefit from:

- fast, convenient online submission

- thorough peer review by experienced researchers in your field

- rapid publication on acceptance

- support for research data, including large and complex data types

- gold Open Access which fosters wider collaboration and increased citations

- maximum visibility for your research: over $100 \mathrm{M}$ website views per year

At BMC, research is always in progress.

Learn more biomedcentral.com/submissions 